\title{
Electromagnetic signals of crust creep motion
}

\section{N. Uvarov, G. I. Drushin, and D. V. Sannikov}

Institute of Cosmophysical Research and Radio Wave Propagation FEB RAS, Kamchatka, Elizovsky district, v. Paratunka, str. Mirnaya 7, 684034, Russia

Received: 21 December 2010 - Accepted: 11 February 2011 - Published: 1 April 2011

Correspondence to: V. N. Uvarov (uvarovvn@gmail.com)

Published by Copernicus Publications on behalf of the European Geosciences Union.

Electromagnetic signals of crust creep motion

V. N. Uvarov et al.

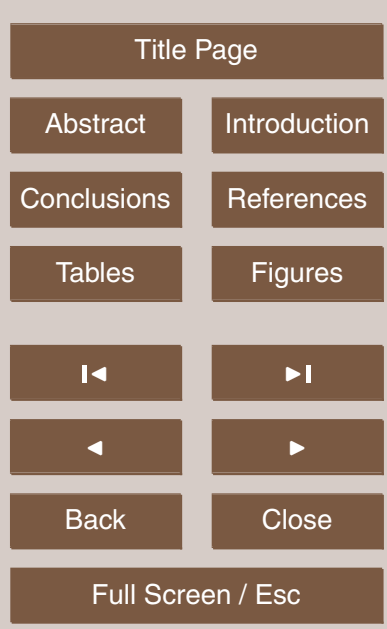

Printer-friendly Version

Interactive Discussion 


\section{Abstract}

A method of registration and allocation of the nearest located sources of natural electromagnetic radiation is developed. Most likely, these sourses in seismically active regions originate from lithisperes. A short description of this method is given. We have 5 carried out a field experiment in the region with small levels of technical noise and high levels of micro-seismic activity (Kamchatka, r. Karimschyna). A number of fragments of the received data are analysed. A large variety of registered signals are shown. It is shown that the most probable source of these signals has lithospheres origin.

\section{Introduction}

10 The question of electromagnetic displays of crust motion, which has more than a century of history (Varley, 1871; Johnston and Parrot, 1989), is still drawing attention. A great number of field observations, laboratory and field experiments and models of mechanic-electromagnetic transformers as for high-energy seismic events (Hayakawa, 1999, 2009; Hayakawa and Molchanov, 2002; Freund, 2006, 2007a, b; Takeuchi, 2006;

Lau, 2006; Guglielmi, 2007) as a slow geological process (creep motion) (Sasai, 2001; Yamazaki, 2009) have been developed. Nevertheless, the investigation and the understanding of the issue are far from complete.

Weakening of radiation in the absorbing media proportionally to frequency and distance between the source and the receiver (Lang, 1974). It means that for effective detection of sources of a lithospheric origin it is necessary to use probably longer waves. To search for these sources follows in a receiver vicinity. Most effectively such detection can be spent in seismically active regions.

The terms of this compromise for electromagnetic radiation are performed in the acoustic frequency range $(20 \mathrm{~Hz}-20 \mathrm{kHz})$. However, this range of natural electromagnetic radiation is dominated by the radiation of lightning discharges of the equatorial zone (atmospherics) and magnetospheres radiation (choruses, whistles,
SED

3, 335-354, 2011

\section{Electromagnetic signals of crust creep motion}

V. N. Uvarov et al.

\section{Title Page}

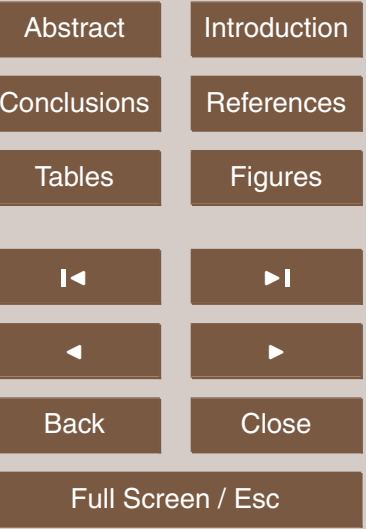

Printer-friendly Version

Interactive Discussion 
whistlers, etc.) (Barr et al., 2000). All this is covered by a sufficiently powerful manmade noise of high-voltage electricity transmission networks. Since we know neither the properties of the spectrum, nor the temporal characteristics of the signals of lithospheres origin, it is not clear on what signs to look for and how to allocate these signals. 5 Only electromagnetic signals with powerful earthquakes were recorded (Hayakawa, 1999, 2009; Hayakawa and Molchanov, 2002). Targeted research aimed at the selection of weak signals of lithospheric origin has not been the reasons mentioned above. It is largely due to the lack of a separation method of lithospheres origin signals with unknown spectral-temporal parameters from a strong masking background of thunderstorms, magnetospheres or man-made radiation.

So, the purpose of this paper is to develop a registration technique, which will allow us to separate faint signals of nearby sources out of a power noise background of a stormy and magnetosphere origin. The obtained results will allow us to make a conclusion on the effectiveness of the technique and to carry out a primary classification

\subsection{Experiment substantiation}

The main parameter determining the effective distance of radiation propagation in an absorbing medium (in lithosphere) is the depth of the skin-layer - the distance at which wave amplitude decreases by $e$ times (Lang, 1974) (Fig. 1). This diagram shows that the distance of propagation decreases with the increase of frequency and conductivity.

Therefore, in order to find sources of lithospheres origin, it is necessary to use radiation with the longest wavelengths and to expect signals from the nearest objects which can create a significant signal in the antenna.

The dominant part of natural radiation is created by lightning located mainly in the 25 equatorial regions and by magnetospheric-ionospheric perturbation (Barr et al., 2000). The distance to these sources is thousands of kilometres.

\section{SED}

3, 335-354, 2011

\section{Electromagnetic signals of crust creep motion}

V. N. Uvarov et al.

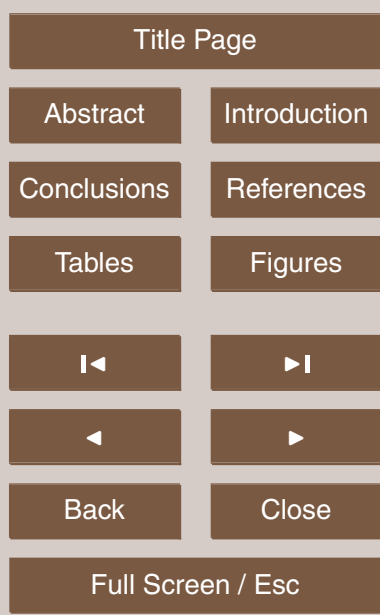

Printer-friendly Version

Interactive Discussion 
Since the sources of lithospheric origin which we try to find, are located in the nearby, one should use a method which allows to detect field of close sources for an effective search.

A field of any charges system can be represented as a power series

$5 \varphi=\sum_{i=0}^{\infty} \frac{K_{i}}{r^{i+1}}$

where $K_{i}$ is $i$-moment of charges system or multipolity; $K_{0}$ is a monopole moment or full charge system; $K_{1}$ is a dipol moment; $K_{2}$ is quadruples moment; $K_{3}$ is octupol moment and so on (Purcell, 1965).

This formula shows that by increasing the multipolarity of expansion components of 10 the radiating system, it reduces the volume of space containing the main energy.

The principle of reciprocity implies that increasing multipolarity of the receiving system similarly reduces the volume of sensitivity. Thus, the antenna of minimal multipolarity must be used for the registration of the remote source - the dipole ones.

Faint signals lithospheres origin can be registered only if they are located close to 15 the receiver. The only way to register such signals, without the influence of distant sources, is to use a quadruples antenna. The quadruples antenna is of no use in radio communications as their sensitivity decreases faster with distance than the dipole antennas. The properties of the quadruples antenna are effective in the allocation of nearby sources, therefore, it is used in our investigations.

20 Figure 2 shows a scheme of a simple quadruples antenna - a system of two dipoles with module equal and opposite dipole moments spaced at distance $d$. Figure 3 shows the evaluation of current amplitude in the antenna from the distance between the source and the quadruples centre derived from a simple geometrical model. Figure 4 shows the dependence of the signals level from a distance for used quadruples the quadruples antenna and near the centre of the frame. The amplitude of the signal slows down by more than $40 \mathrm{~dB}$ at the distance of more than $30 \mathrm{~m}$.

\section{SED}

3, 335-354, 2011

\section{Electromagnetic signals of crust creep motion}

V. N. Uvarov et al.

\section{Title Page}

Abstract

Introduction

Conclusions

References

Tables

Figures

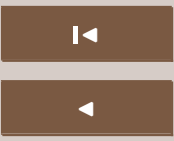

$\rightarrow 1$

Back

$\triangleright$

Close

Full Screen / Esc

Printer-friendly Version

Interactive Discussion 


\subsection{Experimental conditions}

The observation station, where these experiments were carried out, is located at the foot of a blister cone of the Goryachaya mountain. The favourable geological-structural position makes microseismic events frequently observable (Vorodjeykina et al., 1995).

5 The investigations were carried out in the frequency range of $10<f<10000 \mathrm{~Hz}$ (wavelength range in the air $30000>\lambda>30 \mathrm{kM}$ ).

The magnetic field component was used to register radiation. A signal recording was carried out from the quadruples antenna made of two identical frames consistently opposite and connected to an antenna amplifier (Fig. 5). The effective area of each

10 frame is $S_{\mathrm{e}}=N \cdot S=1200 \mathrm{~m}^{2}$, where $N=100$ - number of frame loops, $S=12 \mathrm{~m}^{2}$ geometric area. The distance between the frame centres is $25 \mathrm{~m}$ and were horizontally arranged on the ground surface. Such an antenna does not register signals from the sources in the plane equidistant from the frames and in the far zone, but it is sensitive to the radiation appearing in the vicinity of one of the frames.

15 The electromagnetic condition control is realized by a system of antennas composed of one horizontal, analogues frame of quadruples antenna, and of two vertical issued frame antennas (NS and WE in Fig. 5), which carry out a 24-hour registration of a horizontal magnetic component of the longitudinal and meridional component field. The vertical frames have the effective area of $10000 \mathrm{~m}^{2}$.

20 To minimize man-made noise, the power supply for the equipment was from an independent accumulator source; ground wires of all the units were joined in one point and grounded and the place of the antenna location was preliminarily chosen by a background level indicator. Antenna amplifiers were assembled according to a differential scheme of direct current. The irregularity of frequency characteristics of antenna 25 amplifiers in the range of $10 \div 10000 \mathrm{~Hz}$ was not more than $3 \mathrm{~dB}$. The signals from antenna amplifiers were input to 24-discharge ADC with the sampling rate of $48 \mathrm{kHz}$ by a shielded twisted pair. Registration was carried out by four channels to a NOTEBOOK computer operating from built-in rechargeable batteries. The computer was set

SED

3, 335-354, 2011

\section{Electromagnetic signals of crust creep motion}

V. N. Uvarov et al.

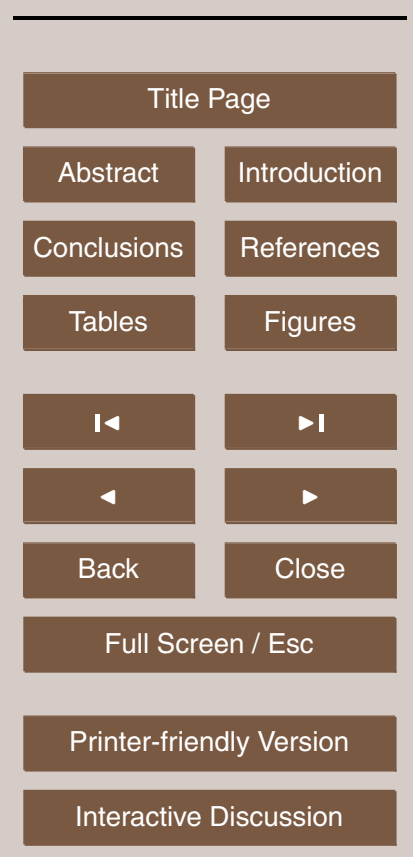

Interactive Discussion 
in a grounded metal building at a distance of $20 \mathrm{~m}$ from the place where the antenna amplifiers A1 and A2 are located. We did not detect any influence of impulse noise on the computer results on the registered signal.

Measurements were performed under stable, clear, windless weather. The nearest 5 power supply to the measuring apparatus is at a distance of more than $100 \mathrm{~m}$. This line is a two-wire cable laid in a metal pipe buried at a depth of $0.5 \mathrm{~m}$. The nearest high-voltage transmission line was held at a distance of more than $5 \mathrm{~km}$. There are no visible objects that can be the source of the signals.

Figure 6 illustrates a recording patch of the signal of quadruples channel (blue 10 line) and of three dipole channels (vertical orientation of magnetic field vector or Zcomponent - green, latitudinal ones - red and longitudinal ones - celadon).

\subsection{Analysis of results}

The analysis of the initial data, in the absence of aprioristic information (duration, spectrum characteristics), does not allow us to explain guiding criteria for anomalies search15 ing.

So, it is ineffective to detect anomalies in space of measurements especially when there is a great volume of raw information. Therefore, synchronous analysis of the spectrochronogram was chosen as the main approach to analyse the received data; it allows us to choose the analysis from a great volume of data. The high flexibility of

20 this approach enables us to choose spectral and time resolution in a wide range for effective detection of the anomalies.

Figure 7 illustrates an example of the four channels spectrochronogram of 87-s patch with three different frequency resolutions.

Such a structure allows us to perform the analysis with a different frequency resolu25 tion. Area of high spectral density at frequencies below $100 \mathrm{~Hz}$ in this figure marked by ellipse. As noted above, such behaviour of an anomaly points at the location of the source in close proximity to one of the frames of the quadruples antenna. The signal from this source in dipole antennas is masked by the much stronger signals of remote

\section{SED}

3, 335-354, 2011

\section{Electromagnetic signals of crust creep motion}

V. N. Uvarov et al.

\section{Title Page}

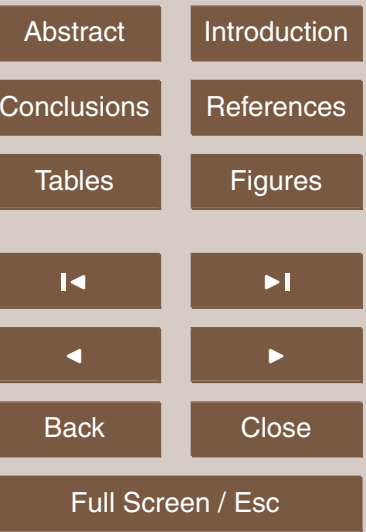

Printer-friendly Version

Interactive Discussion 
sources of non-lithospheres (lightning) origin. The second column and the two vertical lines indicate a splash of about $5 \mathrm{~s}$ duration which appeared both in quadruples as in all three dipole channels. And finally, the third column shows a splash of about $2 \mathrm{~s}$ duration which appeared only in the 4th dipole channel. In both latter cases, the increasing 5 radiation in the quadruples channel is accompanied by increasing radiation of dipole channels.

For such a complex structure of the spectrum of recorded signal one can suggest the following explanation. The radiation source is sufficiently long and powerful. Part of the source is located in the proximity of one of the frames of the quadruples antenna and 10 buried into the ground, absorbing high-frequency emission. Powerful radiation in the high-frequency signal dipole channels can be explained by the fact that the remote part of the source takes up position on the day surface. In this case, the high-frequency radiation will be transmitted in the atmosphere and will be available to register quadruples antenna. Example of spectrochronogram of $87-\mathrm{s}$ patch with three different frequency 15 resolutions.

Left column corresponds to the upper frequency range limit $2000 \mathrm{~Hz}$, the middle column $400 \mathrm{~Hz}$, and the right column $100 \mathrm{~Hz}$. The upper row of images contains spectrohronogramms of quadruples channel. The second top row contains spectrohronogramms of Z-channel, the third - the latitude channel and the fourth - the longitudinal 20 ones.

As seen from Fig. 4, the size of the sensitivity zone on $70 \mathrm{~dB}$ level does not exceed $100 \mathrm{~m}$. Therefore, the most likely assumption is that these signals are related to local slow tectonic processes (creep motion). Therefore, the registered signal belongs to the lithospheres source if within a circle with a radius of at least $100 \mathrm{~m}$ round the quadruples antenna there are no sources of another origin. There were no visible objects, which would become sources of such radiation.

Figure 8 shows the splashes collection in quadruples channel not displayed in dipoles channels. Panel 1 illustrates considerable intensity of the quadruples signal, whereas in the lower panels 2, 3 and 4 the intensity of the signal is less or is absent.

\section{SED}

3, 335-354, 2011

\section{Electromagnetic signals of crust creep motion}

V. N. Uvarov et al.

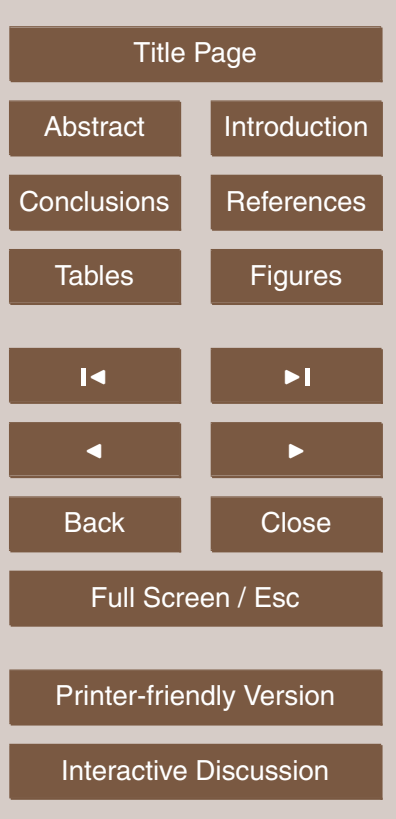


The duration of disturbances in the quadruples channel is from several seconds to several tens of seconds.

It is quite often the case when the display of the signal in the quadrupole channel occurs simultaneously with the display in dipole channels. Figure 9 illustrates the

5 splashes collection in which the most intense anomaly occurs in the frequency range up to $400 \mathrm{~Hz}$. For these cases the display is observed in panels 3 and 4 which correspond to the dipole channels of the horizontal magnetic component and is almost not observed for the vertical magnetic component. It means that the radiation source is located in the immediate vicinity of the quadruples antenna. The lack of display in the 10 antenna channel 2 (Z-components) means that the vector of the magnetic component is horizontally oriented in the localization of the antenna, i.e., one is a source of small extent in the immediate vicinity of the quadruples antenna. The signal duration in this case is from 1-2s to $10-15 \mathrm{~s}$. Moreover, there are a number of cases when the frequency of the maximum of spectral density is a function of time (patches $7,14,16,19$, 15 20, 22).

Figure 10 shows the splashes collection that also contain the display of both the quadrupole and dipole channels, but in this set, the dipole channel display is a much wider frequency range up to $2000 \mathrm{~Hz}$. Just like in the previous set in Fig. 9, the duration of splashes is 5-10 s. Sometimes the display of the vertical component of the magnetic field is observed in channel 2 (patches $1,2,3,8,9,16,18,20,27,33,34,35$, $36,37)$. Furthermore, here one can observe a considerable difference in splash width at different frequencies (patches $7,9,10,12,13,14,15,17,21,22$ ) and a more complicated frequency-time dependence (patches $3,17,21$ ). In this case, it is possible to assume that the radiation source is partially located in a sensitivity zone of quadruples antenna, i.e., close enough; but the part of its radiation extends to the atmosphere, i.e., the source borders on the ground surface and has enough extension.

\section{Electromagnetic signals of crust creep motion}

V. N. Uvarov et al.

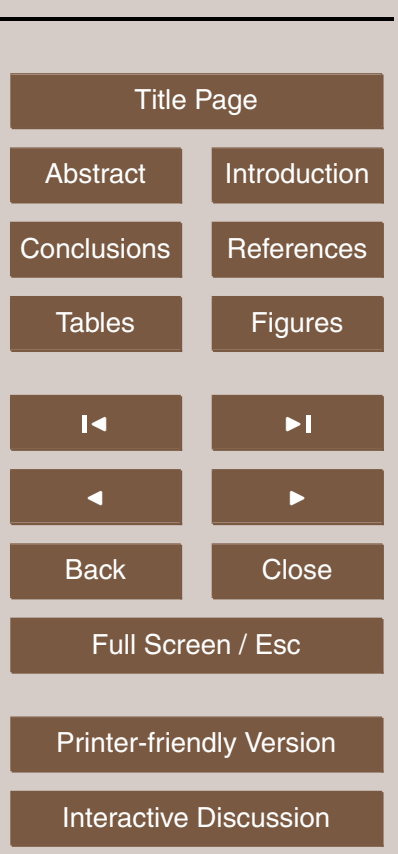




\section{Conclusions}

The method of registering the nearest sources of the natural electromagnetic radiation is developed.

The method allows us to single out the weak signals of the nearest sources from the 5 powerful background signals of remote sources.

The results of the method application in the seismically active zone of Kamchatka showed the existence of several kinds of electromagnetic signals.

The major part of radiation energy of closely located sources falls within the low frequency range of $5-1000 \mathrm{~Hz}$.

10 Two kinds of signals were discovered: displayed only in quadruples channel and displayed as in quadruples as in dipole channels.

It was found that the signals in a quadruples channel appear on average every 5$10 \mathrm{~s}$.

The duration of the splashes is in the range from 0.1 to $30 \mathrm{~s}$.

15 The bursts of radiation in the quadruples channel are most likely associated with widespread creeping deformations of the crust, forming a relief and widespread in the zone of high seismic activity.

This method can be used for the monitoring and the analysis of tectonic activity of earth crust.

Acknowledgements. This work performed under the grant of FEB RAS 09-III-A-02-042 "Development of the method of separating the radiation lithospheres origin of ELF-VLF range".

The authors thank the chief engineer V. M. Puchov for active participation in the realization of the experiments.

\section{References} 62, 1689-1718, 2000.

SED

3, 335-354, 2011

\section{Electromagnetic signals of crust creep motion}

V. N. Uvarov et al.

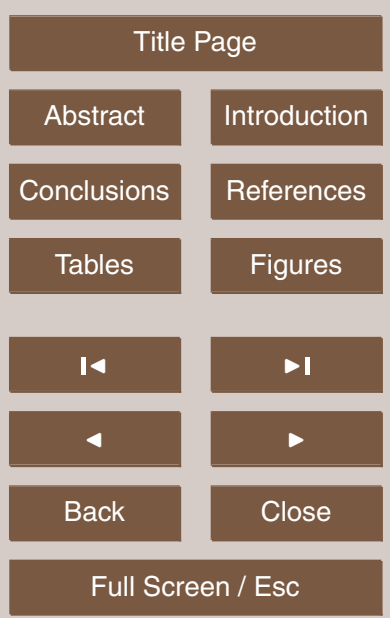

Printer-friendly Version

Interactive Discussion 
Freund, F. T.: Pre-earthquake signals - Part I: Deviatoric stresses turn rocks into a source of electric currents, Nat. Hazards Earth Syst. Sci., 7, 535-541, doi:10.5194/nhess-7-535-2007, 2007a.

Freund, F. T.: Pre-earthquake signals - Part II: Flow of battery currents in the crust, Nat. Hazards Earth Syst. Sci., 7, 543-548, doi:10.5194/nhess-7-543-2007, 2007b.

Freund, F. T., Takeuchi, A., and Bobby, W. S. L.: Electric currents streaming out of stressed igneous rocks - A step towards understanding pre-earthquake low frequency EM emissions, Phys. Chem. Earth, 31, 389-396, 2006.

Guglielmi, A. V.: Ultra-low-frequency electromagnetic waves in the Earth's crust and magnetosphere, Phys.-Usp., 50, 1197-1216, 2007.

Hayakawa, M. (Ed.): Athmospheric and Ionospheric Electromagnetic Phenomena Associated with Earthquakes, Terra Scientific Publishing Company, Tokyo, 1999.

Hayakawa, M. (Ed.): Electromagnetic Phenomena Associated with Earthquake, Transworld Research Network, Trivandrum, India, 279 pp., 2009.

15 Hayakawa, M. and Molchanov, O. A. (Eds.): Seismo Electromagnetics Litosphere-AtmosphereIonosphere Coupling, TERRAPAB, Tokyo, 477 pp., 2002.

Johnston, M. J. S. and Parrot, M. (Eds.): Seismoelectromagnetic Effects, Special Issue, Phys. Earth Planet. In., 57, 1-177, 1989.

Lang, Ê. R.: Astrophysical formulae. A compendium for the physics and astrophysics, Springer-

20 Verlag, Berlin Heidelberg New York, 1974.

Purcell, E. M.: Electricity and Magnetism, Berkeley Physics Course. V.2, Mcgraw-hill book company, 1965.

Sasai, Y.: Tectonomagnetic modeling based on the piezomagnetism: a reviev, Ann. Geofis., 44(N2), 361-368, 2001.

25 Varley, C. F.: Subterranean electrical disturbances, Nature, 3, 492-496, 1871.

Vorodjeykina, L. A., Skorobogatsko, L. S., and Sokolov, V. A.: Experimental and methodological work on the application of structural-geological, hydrological, geophysical and remote search criteria of thermal waters in enclosed areas, Report Avachinskaya party Kamchatgeologija, The results of the work carried out on Petropavlovskaja Square. v. Termalny, FGU TFI, 980

30 pp., 1995 (in Russian).

Yamazaki, K.: Calculation of the piesomagnetic field arising from uniform regional sterss in inhomogeneously magnetized crust, Earth Planets Space, 61, 1163-1168, 2009.

\section{Electromagnetic signals of crust creep motion}

V. N. Uvarov et al.

\section{Title Page}

Abstract

\section{Full Screen / Esc}

Printer-friendly Version

Interactive Discussion 


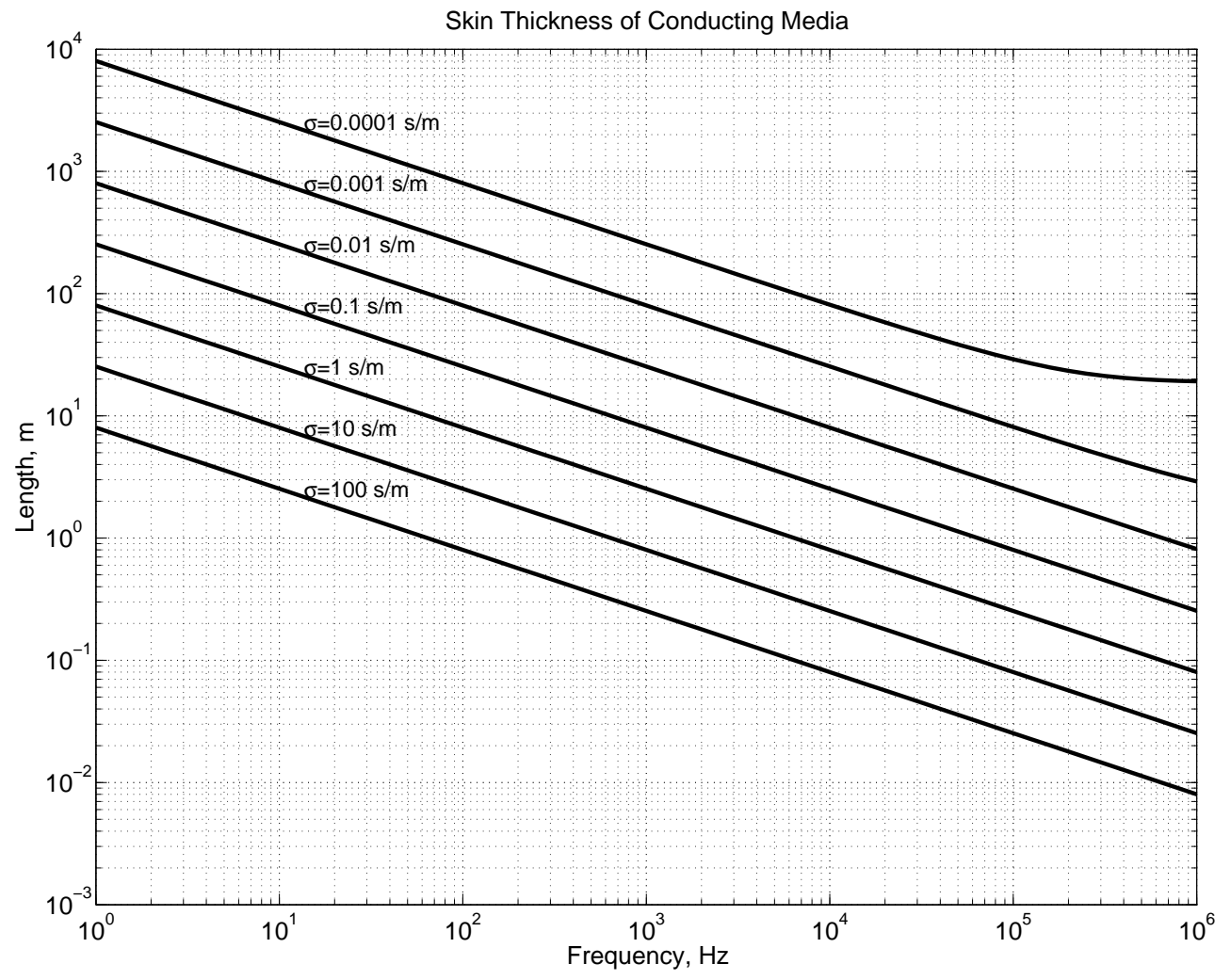

SED

3, 335-354, 2011

\section{Electromagnetic signals of crust creep motion}

V. N. Uvarov et al.

Title Page

Abstract

Introduction

Conclusions

References

Tables

Figures

14

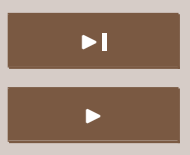

Back

Close

\section{Full Screen / Esc}

Printer-friendly Version

Fig. 1. Skin length via frequency for different conductivity.

Interactive Discussion 


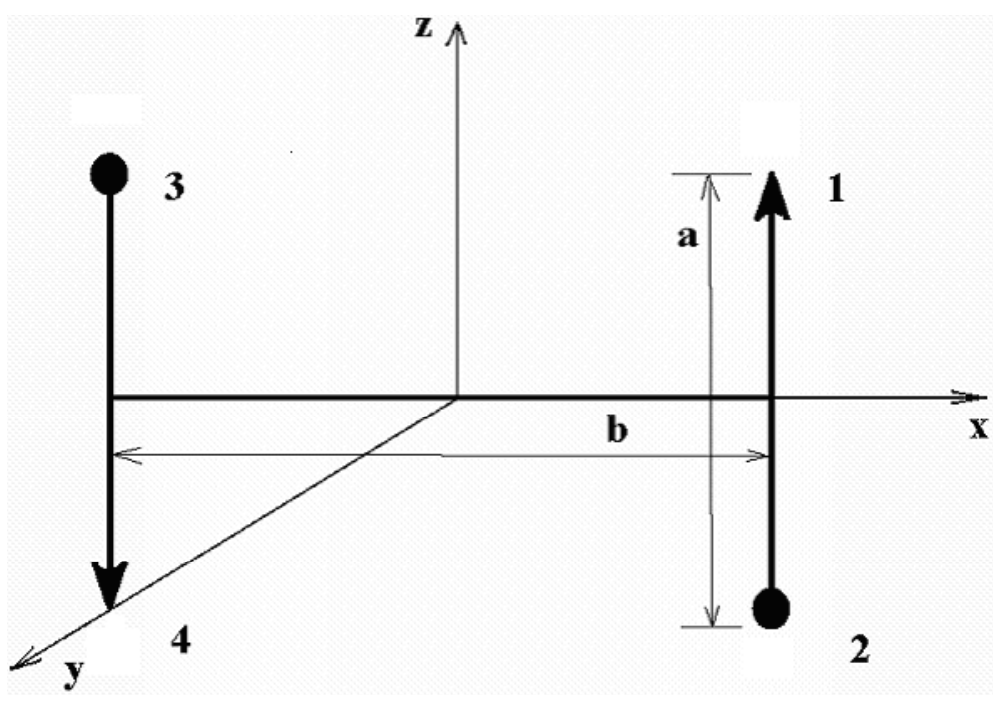

Fig. 2. Quadruple as system of two equal dipoles. $a$ - size of dipole. $b$-distance between the centres of the dipoles.

\section{SED}

3, 335-354, 2011

\section{Electromagnetic} signals of crust creep motion

V. N. Uvarov et al.

Title Page

\section{Abstract \\ Introduction \\ Conclusions \\ References}

Tables

Figures

14

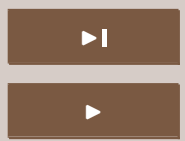

Back

Close

Full Screen / Esc

Printer-friendly Version

Interactive Discussion 


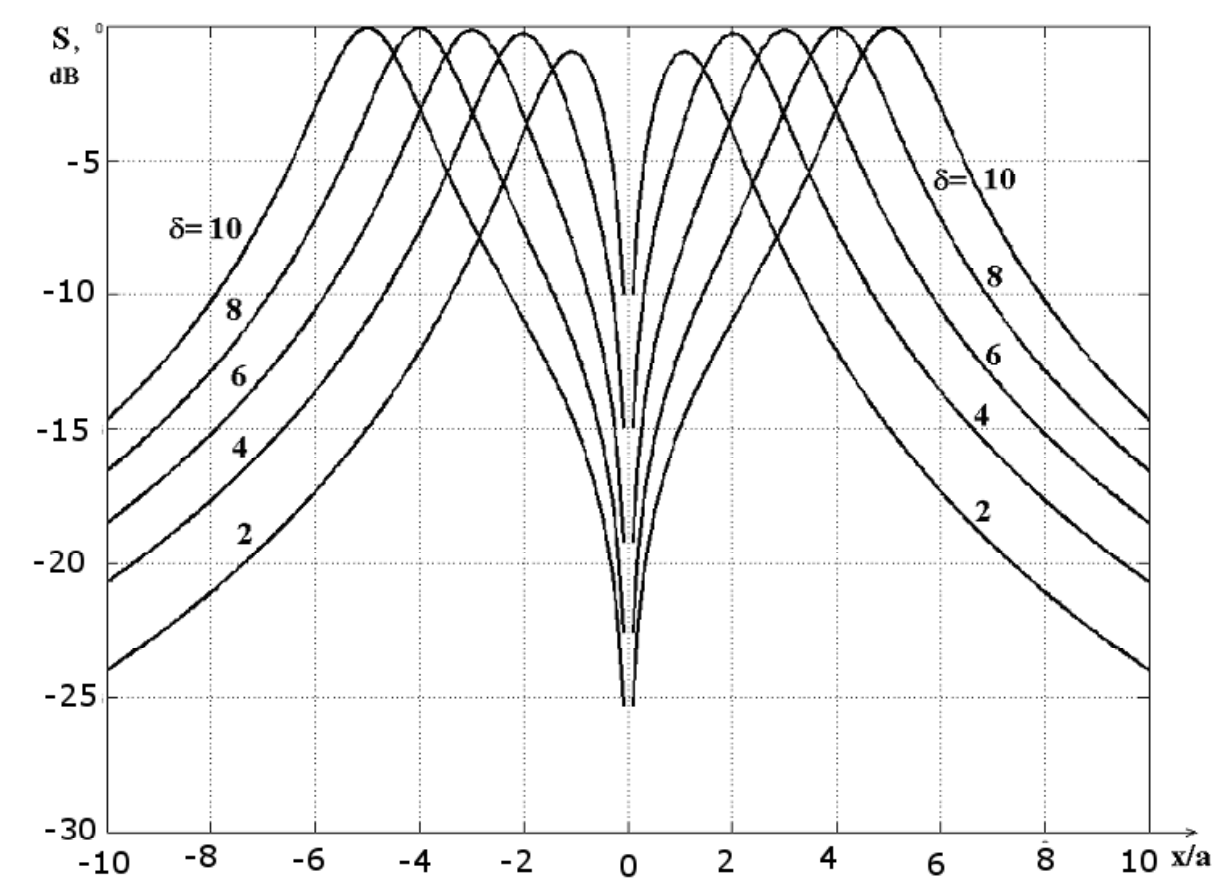

Fig. 3. Signal intensity via comparative position of source for different $\delta=\frac{b}{a}$. Symbol as on Fig. 2.

\section{SED}

3, 335-354, 2011

\section{Electromagnetic} signals of crust creep motion

V. N. Uvarov et al.

\section{Title Page}

Abstract

Introduction

Conclusions

References

Tables

Figures

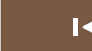

14

Back

Close

\section{Full Screen / Esc}

Printer-friendly Version

Interactive Discussion

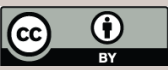


SED

3, 335-354, 2011

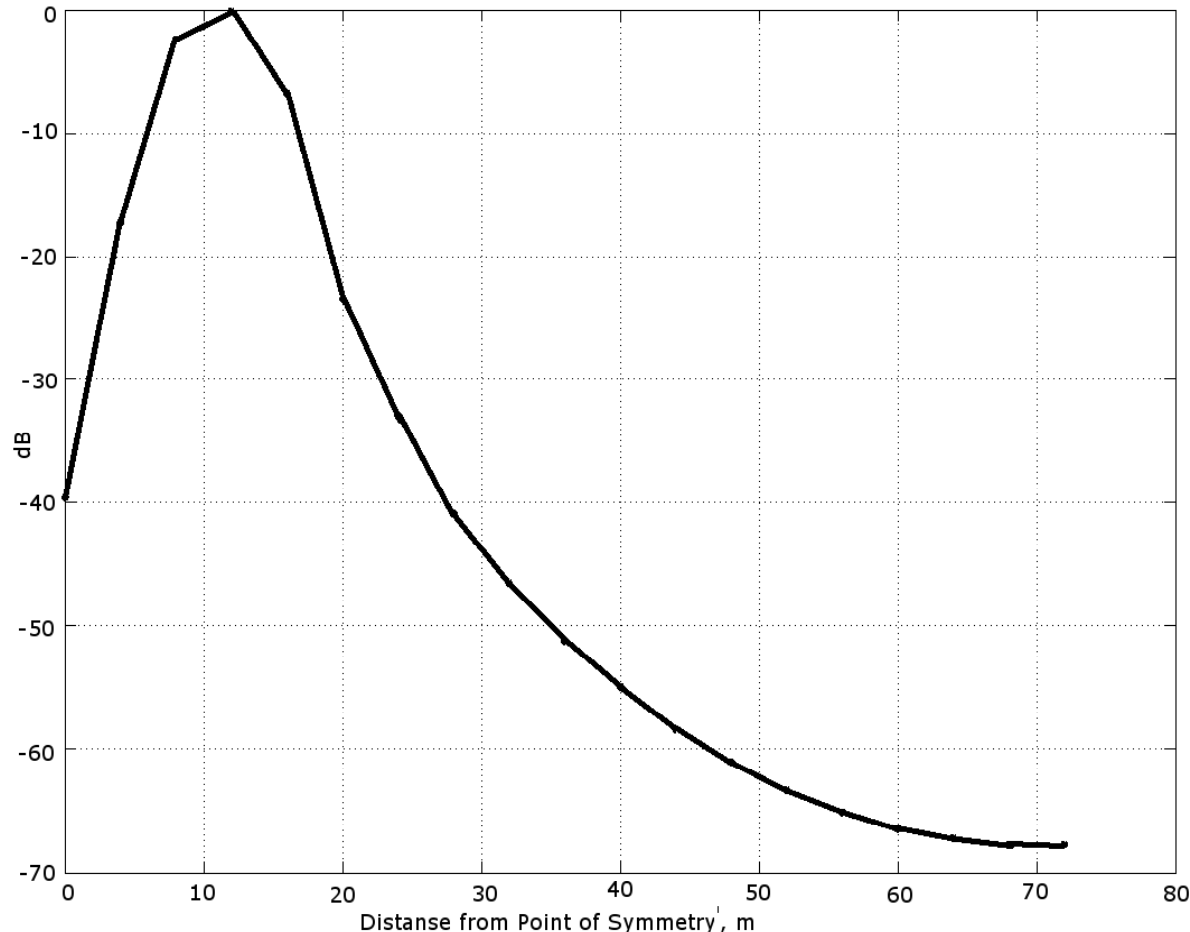

\section{Electromagnetic signals of crust creep motion}

V. N. Uvarov et al.

Title Page

Abstract

Introduction

Conclusions

References

Tables

Figures

14

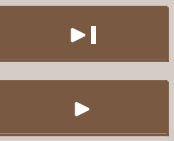

Back

Close

Full Screen / Esc

Printer-friendly Version

Interactive Discussion

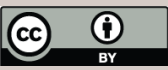




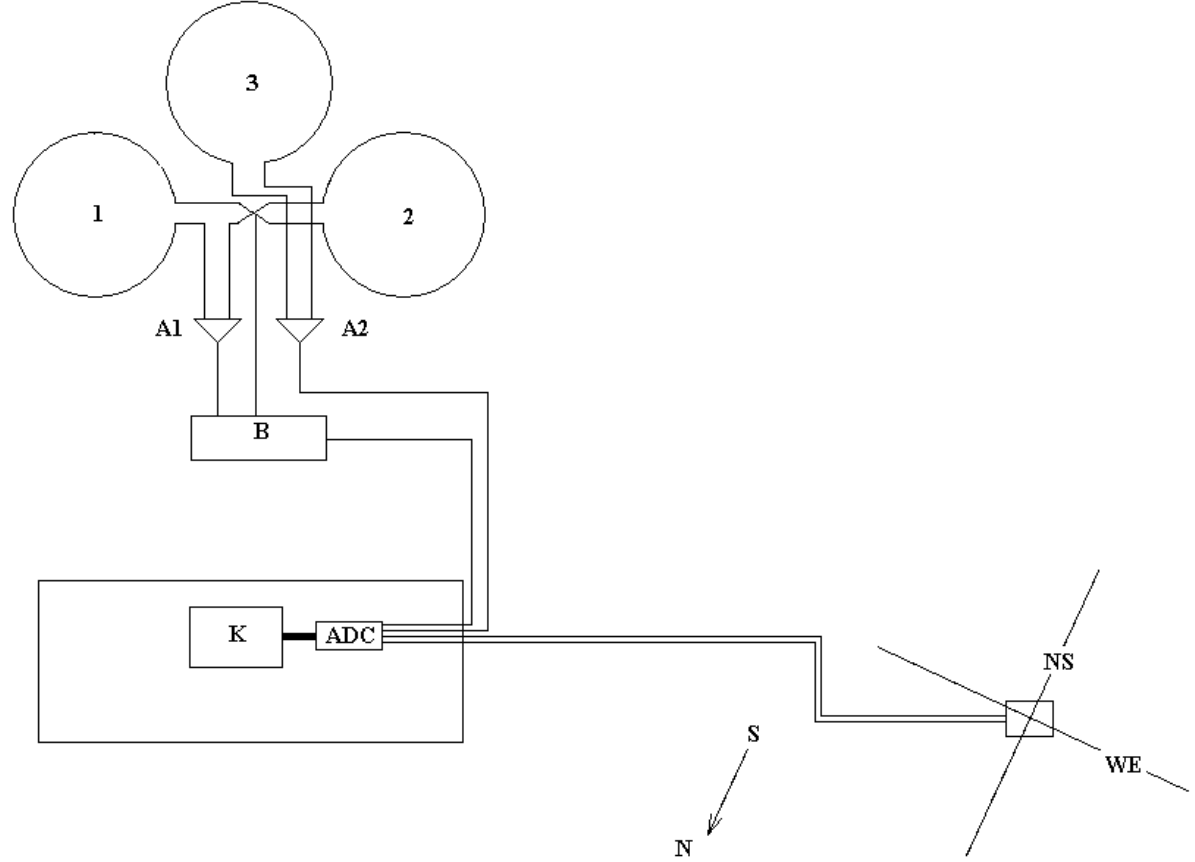

Fig. 5. Diagram of experiment. 1 and 2 - frames of quadrupole antenn. 3 - antenn of magnetic Z-component. A1, A2 - antennas amplifiers of quadrupole and Z-channels. B - the symmetrizing device of quadrupole antenn. ADC - digitizer. NS and WE - antenns of horizontal components of a magnetic field with antenna amplifiers. $\mathrm{K}-$ the registering computer.

\section{Electromagnetic signals of crust creep motion}

V. N. Uvarov et al.

\section{Title Page}

\section{Abstract}

Introduction

Conclusions

References

Tables

Figures

14

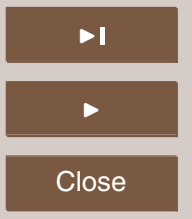

Back

Close

\section{Full Screen / Esc}

Printer-friendly Version

Interactive Discussion 


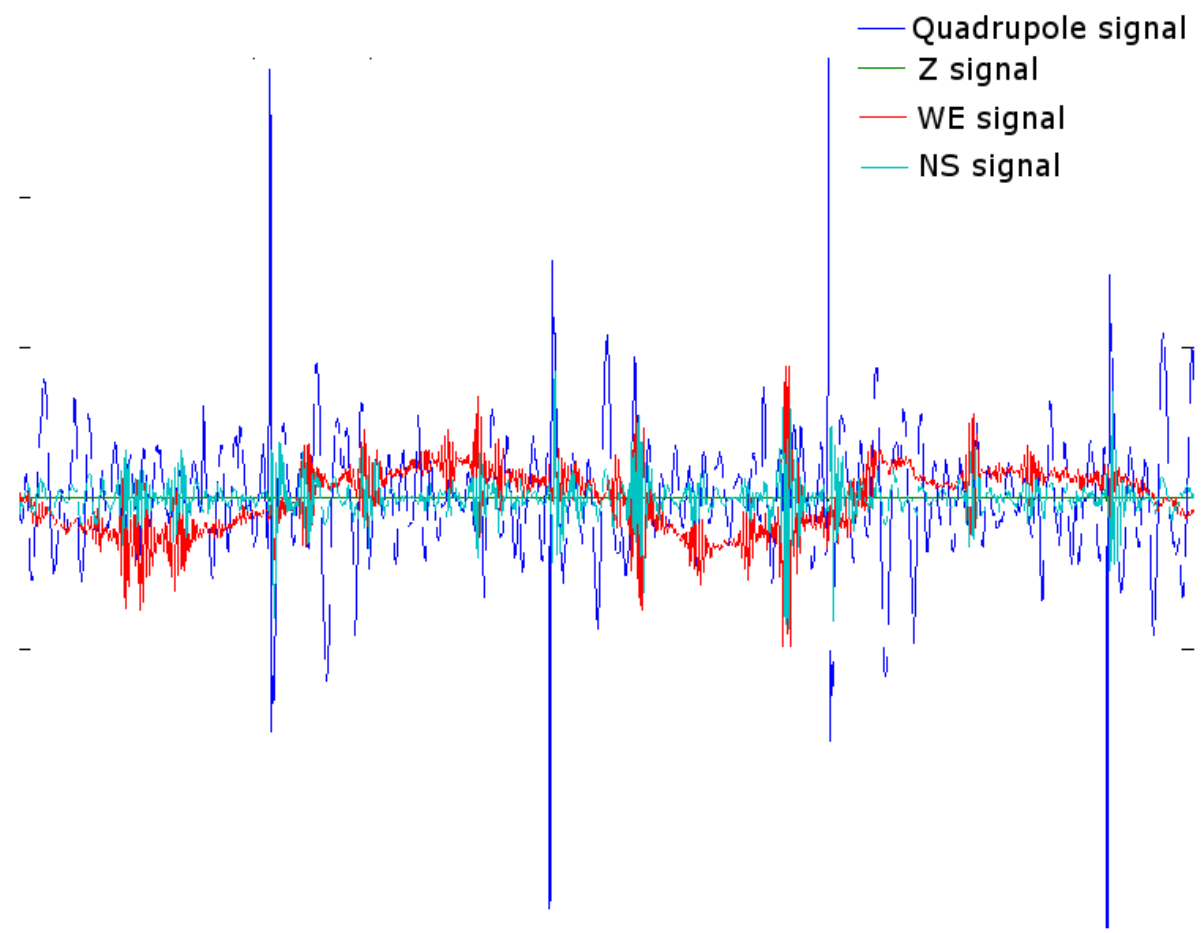

Fig. 6. Initial wave form of signals. 1 (blue line) - quadruples signal, 2 (green) - vertical orientation of magnetic field, 3 (red) - latitudinal component, 4 (celadon) - longitudinal component.

\section{Electromagnetic signals of crust creep motion}

V. N. Uvarov et al.

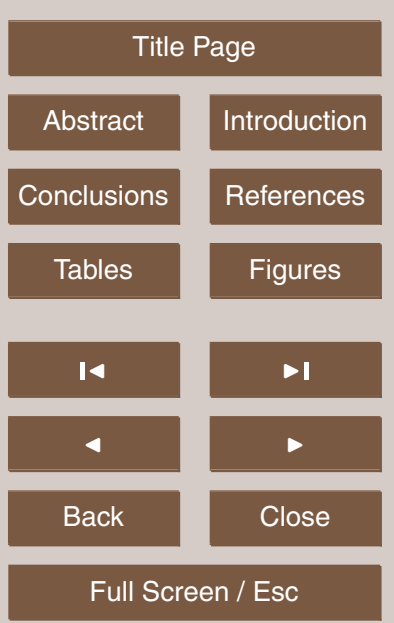

Printer-friendly Version

Interactive Discussion 

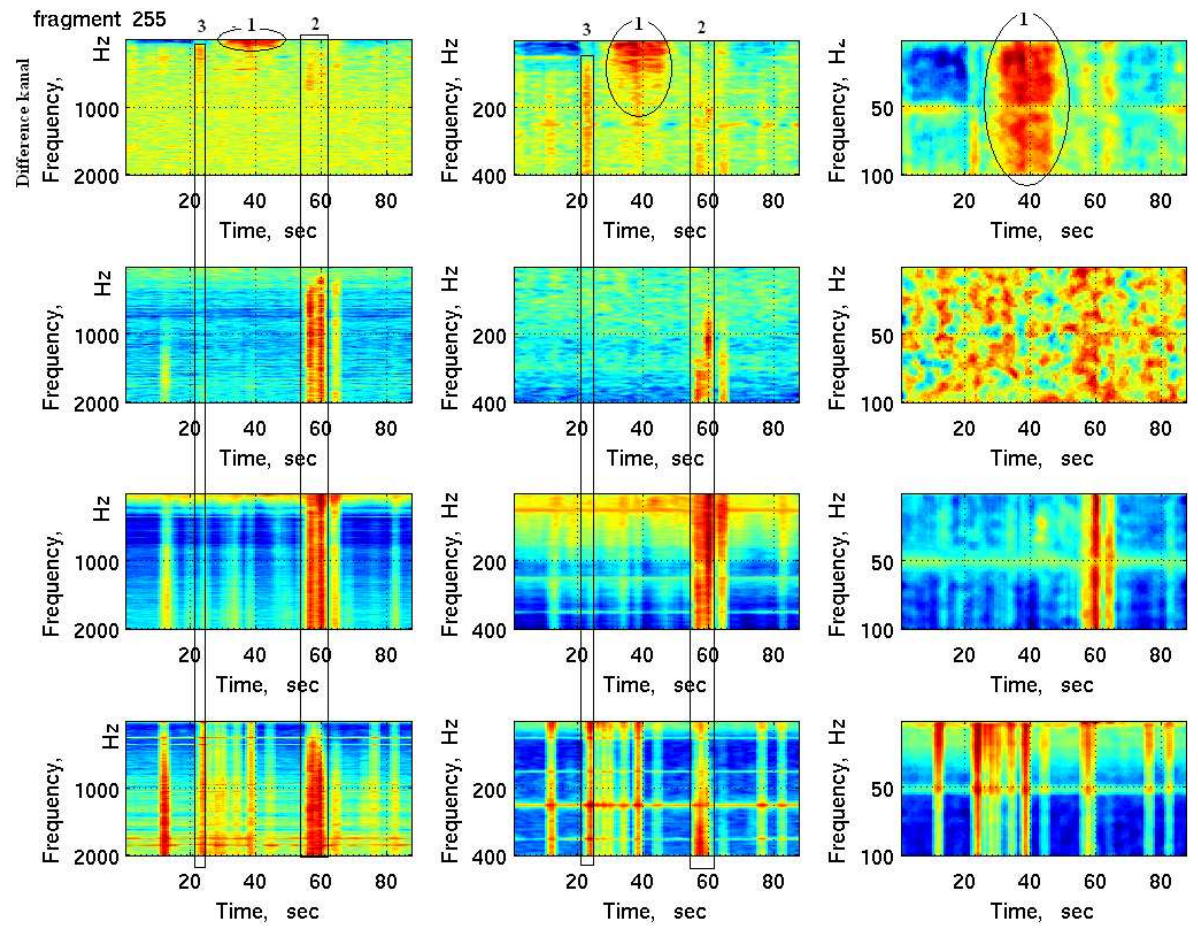

SED

3, 335-354, 2011

\section{Electromagnetic signals of crust creep motion}

V. N. Uvarov et al.

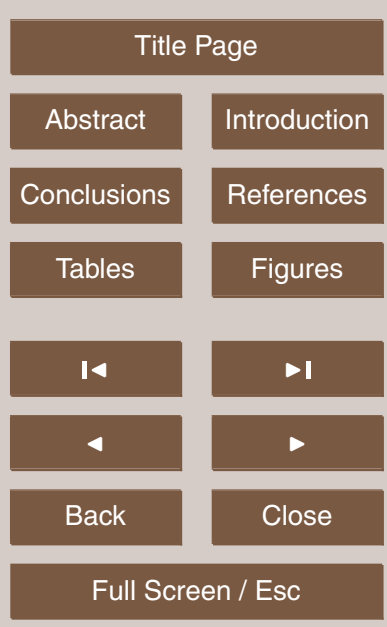

Fig. 7. Example of spectrocronograms of 4 channels with 3 frequency resolutions.

Printer-friendly Version

Interactive Discussion

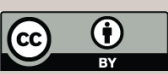




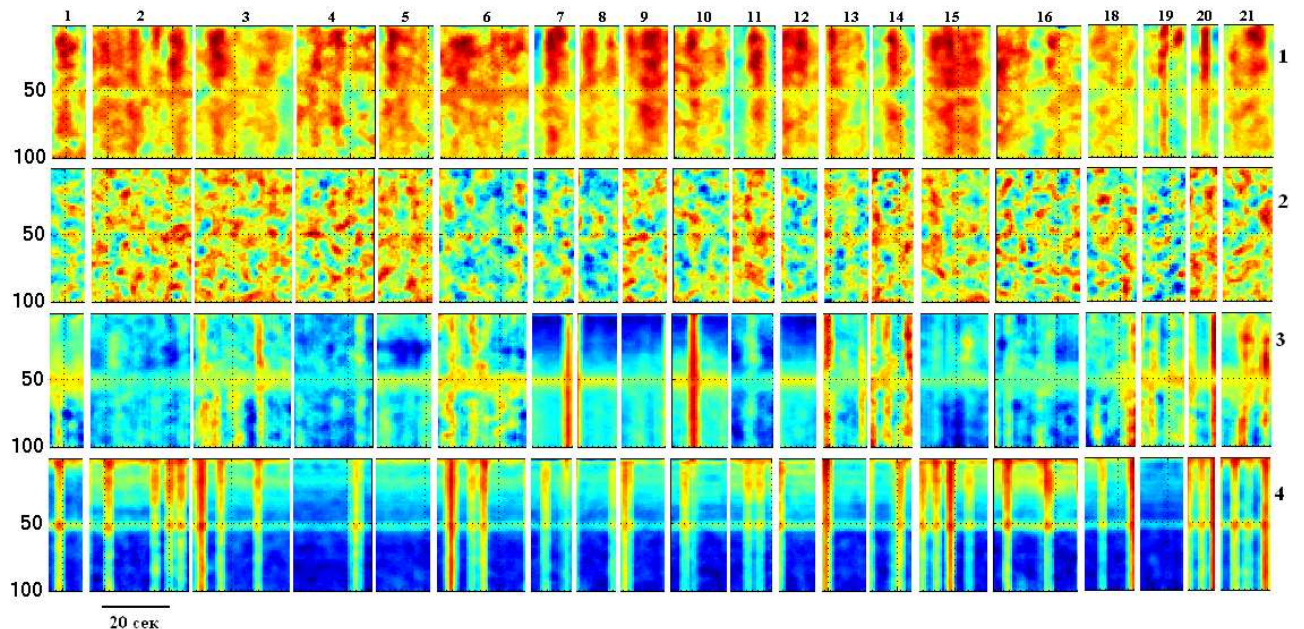

Fig. 8. Collection of long low frequency signals without dipoles display. The upper row quadruples channel. The second top row - Z-channel, the third row - the latitude channel, the fourth - the longitudinal ones.

\section{SED}

3, 335-354, 2011

\section{Electromagnetic signals of crust creep motion}

V. N. Uvarov et al.

Title Page

Abstract

Introduction

Conclusions

References

Tables

Figures

14

4

Back

Close

\section{Full Screen / Esc}

Printer-friendly Version

Interactive Discussion

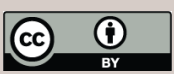




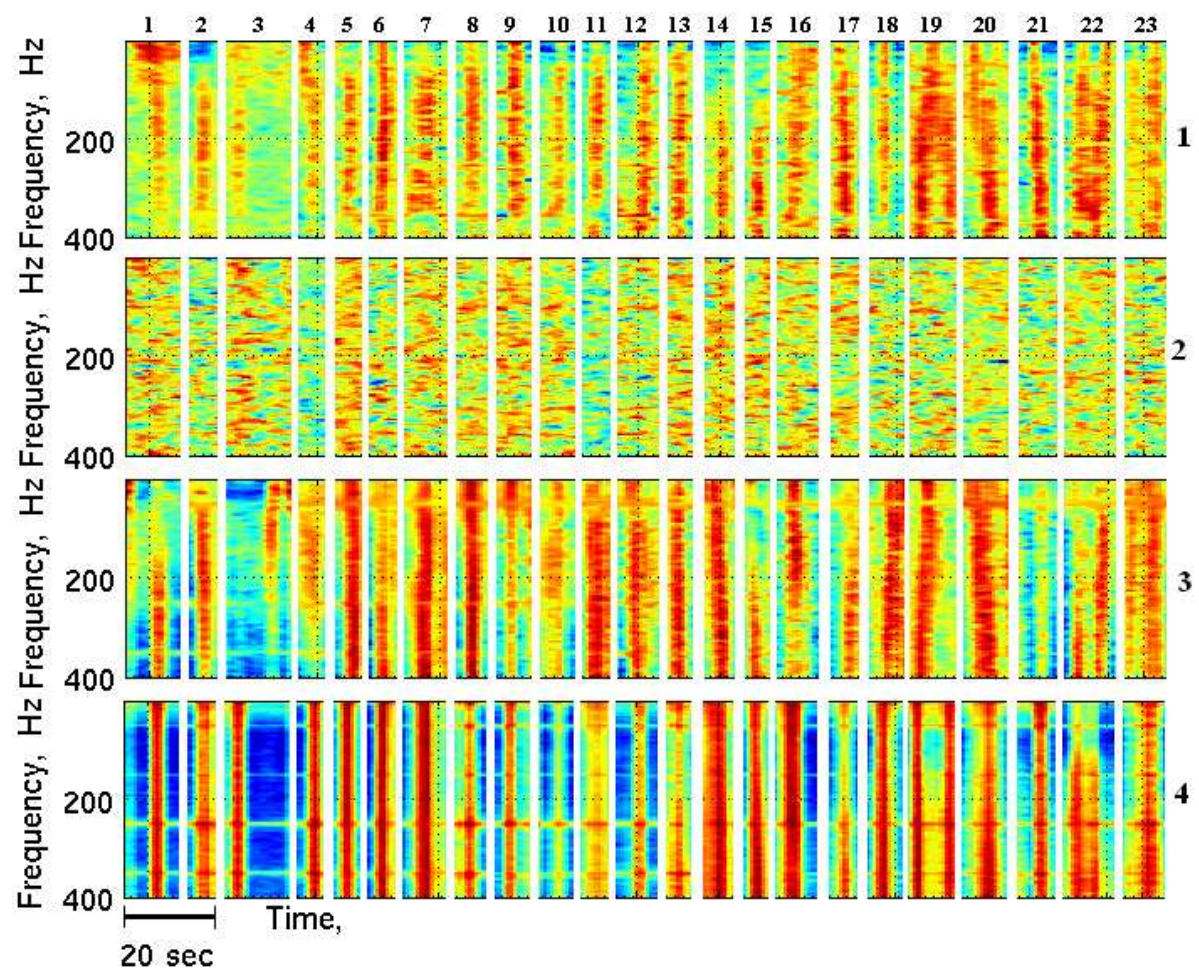

Fig. 9. Collection of middle frequency signals having dipoles display. Designation of channels as in Fig. 8.

\section{SED}

3, 335-354, 2011

\section{Electromagnetic signals of crust creep motion}

V. N. Uvarov et al.

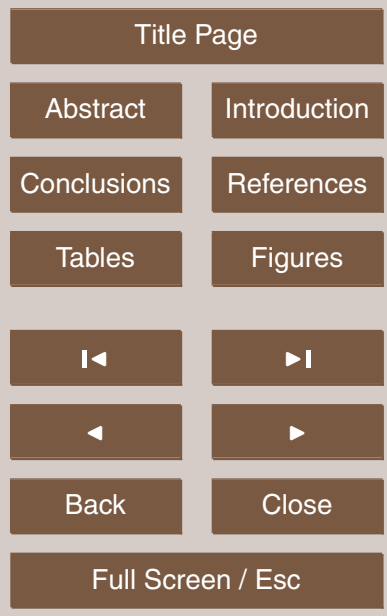

Printer-friendly Version

Interactive Discussion

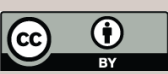




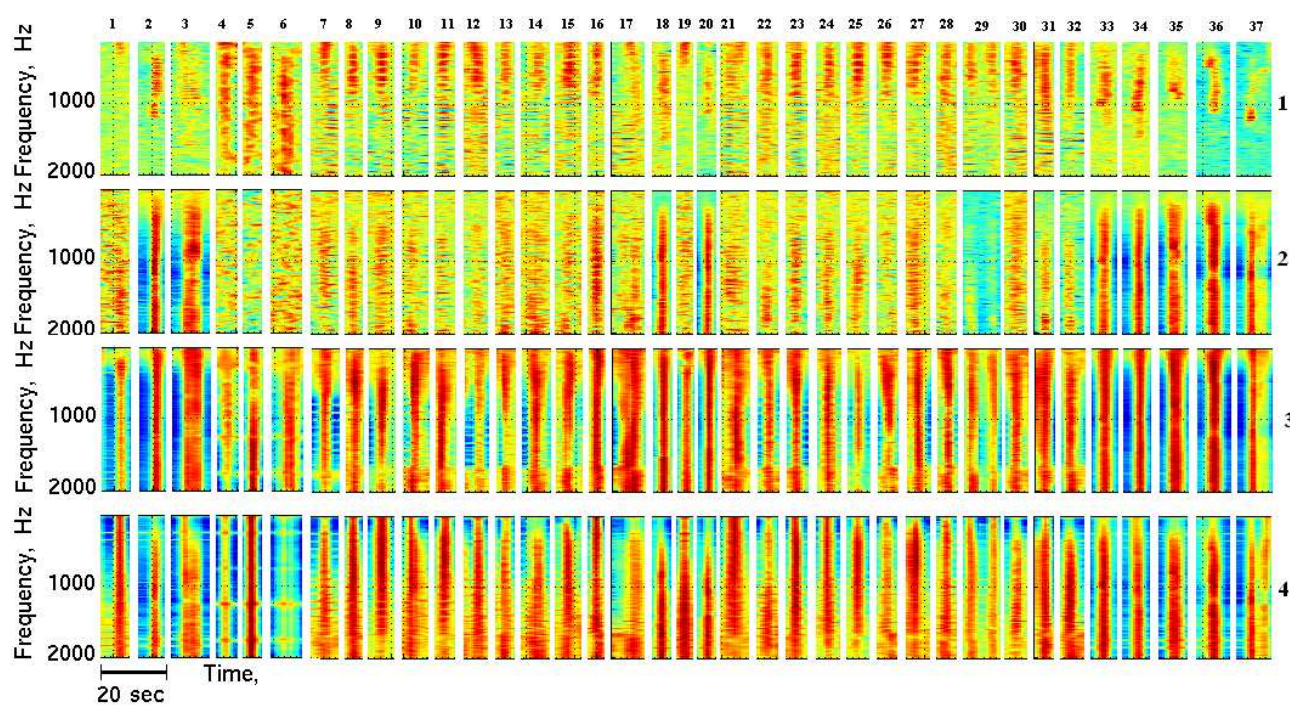

Fig. 10. Collection of high frequency signals having dipoles display. Designation of channels as in Fig. 8.
SED

3, 335-354, 2011

\section{Electromagnetic signals of crust creep motion}

V. N. Uvarov et al.

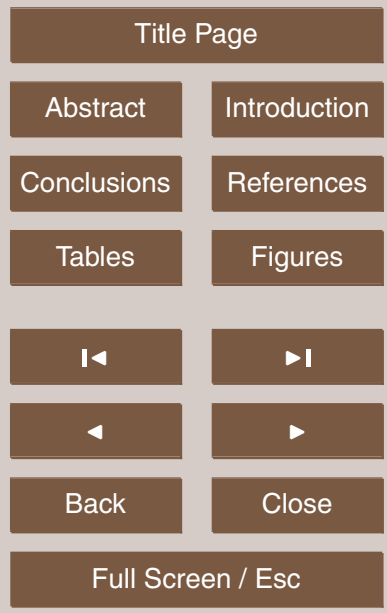

Printer-friendly Version

Interactive Discussion

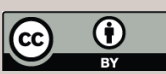

